\title{
Identifikasi Faktor Kritis dalam Perancangan Jasa Rental Mobil
}

\author{
Rahman, R. A., Negoro, P. N., dan Kunaifi, A. \\ Departemen Manajemen Bisnis, Fakultas Bisnis dan Manajemen Teknologi, \\ Institut Teknologi Sepuluh Nopember (ITS) \\ e-mail: aang_kunaifi@mb.its.ac.id
}

\begin{abstract}
Abstrak-Bisnis jasa rental mobil semakin berkembang setiap tahunnya setiap tahunnya. Tujuan dari penelitian ini adalah mengidentifikasi faktor faktor kritis dari sisi produk dan jasa yang dapat meningkatkan kepuasan konsumen. Penelitian ini menggunakan penelitian deskriptif kuantitatif dimana menilai apakah faktor dari metode Product Service System yang berpengaruh signifikan dalam bisnis rental mobil. Faktor kebutuhan dari PSS rental mobil yang digunakan dalam rancangan model PSS bisnis rental mobil berjumlah 38, yang terdiri dari 26 faktor kritis technical artefact dan 12 faktor services. Setelah dilakukan product and service realtionship matrix yang merupakan adaptasi dari house of quality, penelitian ini menghasilkan 6 faktor kritis dengan nilai hubungan tertinggi dari tabel product and service analysis matrix yang ada, tiga faktor kritis dari sisi produk adalah related product, availability dan flexibility. Faktor kritis dari sisi jasa adalah required resource, estimated result dan location of service application.
\end{abstract}

Kata Kunci-Rental Mobil, Product and Service Analysis Matrix.

\section{PENDAHULUAN}

B ANYAK rental mobil mengalami permasalahan seperti ketersedian dan spesifikasi mobil yang dibutuhkan [1] mengatakan mobil dengan kapasitas kabin yang lebih lebar seperti Avanza, Xenia, dan Grand Livina paling banyak disewa saat liburan dan libur lebaran tetapi tidak setiap rental mobil memiliki mobil dengan spesifikasi tersebut. Menurut [2] semakin meningkatnya permintaan produk yang bervariasi akan membuat rental mobil sulit untuk menentukan mobil dengan spesifikasi yang sesuai dengan permintaan konsumen. Namun, terdapat rental mobil yang semakin sukses dan memiliki armada yang banyak. Sebagai contoh adalah rental mobil Atrans yang saat ini mengembangkan bisnisnya dengan menyediakan jasa penyedia rental mobil berbasis aplikasi online. Atrans mendapatkan order dengan lebih baik karena melakukan inovasi dari sisi aplikasi dan juga sistem bisnis rental mobil yang ditingkatkan [3]. Oleh karena itu kurangnya ilmu yang membahas apa yang diperlukan jasa rental mobil dapat berkembang membuat beberapa pemilik bisnis rental mobil kesulitan menentukan keputusan. Permintaan konsumen untuk produk semakin beragam dan kaingin untu dapat kostum suatu produk dengan kehendak pribadi [4]. Hal tersebut terjadi karena meningkatnya kesadaran konsumen akan produk yang baik dan berkualitas. Oleh karena itu diperlukan diferensiasi produk yang sesuai dengan menyelaraskan antara produk dan jasa yang diberikan kepada konsumen sehingga dapat meningkatkan kepuasan konsumen [5].

Meneliti mengenai kebutuhan dalam bisnis rental mobil menjadi hal yang penting. [2] menyatakan kebutuhan dalam suatu bisnis yang diperoleh dapat membantu dalam meengembangkan suatu usaha agar tetap bertahan dalam persaingan bisnis. Maka dari itu penelitian ini berfokus pada beberapa aspek yaitu faktor kritis dari sisi produk dan faktor dari sisi jasa.

\section{TINJAUAN PUSTAKA}

Product Service System (PSS) pertama kali digagaskan oleh [6] yang didefinisikan sebagai sebuah sistem produk, jasa, antara pemain dan infrastruktur pendukung yang secara berlanjut berusaha untuk tetap kompetitif, memuaskan kebutuhan pelanggan dan memiliki dampak lingkungan yang kecil daripada bisnis model tradisional.

\section{METODOLOGI PENELITIAN}

\section{A. Jenis Data}

Data primer merupakan data karakteristik demografi responden yang diperoleh menggunakan metode survei kuisoner pada responden yang merupakan pelanggan dari rental mobil dengan transaksi sewa mobil 3 bulan terakhir. Data yang diambil adalah data kuisoner penelitian dalam demografi responden dan tabel jenis mobil dan harga sewa untuk analisis tabulasi silang.

\section{B. Pengumpulan Data}

Penelitian dilakukan dengan menggunakan metode survei melalui kuisoner yang disebar secara offline di wilayah kediri dengan target responden pengguna jasa rental mobil dalam 3 bulan terakhir. Jumlah responden selama penyebaran kuisoner pada bulan September 2017 sampai November 2017 yang disebar sebanyak 150 dan kuisoner yang kembali adalah 115 dengan respons rate $0,77 \%$ dengan sampel menggunakan porposive sampling. Analisis yang digunakan Product and Service Analysis Matrix [7] dengan faktor yang diambil dari [2].

\section{ANALISIS DAN PEMBAHASAN}

\section{A. Bisnis Model Kanvas Rental Mobil}

Bisnis model kanvas ini merupakan bisnis model kanvas rental mobil dengan target konsumen perorangan [8]. Key Partner dari rental mobil ini adalah pemilik mobil yang disewakan, bengkel mobil, penyedia website, dan dealer mobil. Key Activities dari rental mobil adalah jasa sewa mobil, antar jemput mobil sewaan, pencatatan jam sewa, promosi online, promosi offline, dan monitoring kondisi mobil secara berkala. Key Recource dari rental mobil terbagi menjadi PC, Mobil yang disewakan dan garasi serta kantor. Value proposition dari rental mobil adalah jasa sewa mobil murah yang fleksibel dan memberikan mobil yang berkualitas dan mudah dijangkau masyarakat. Customer relationship diperoleh dengan cara fasilitas penambahan 


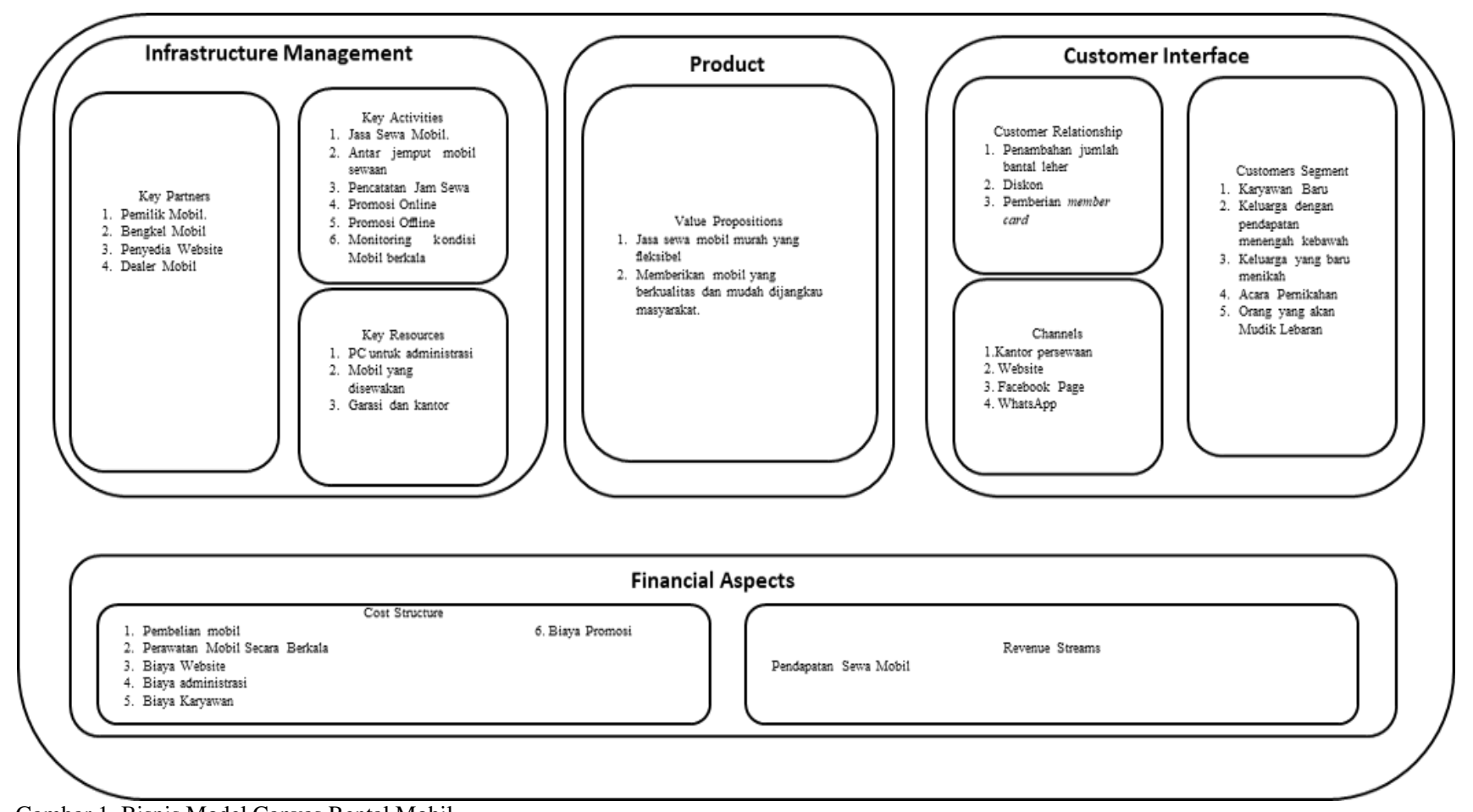

Gambar 1. Bisnis Model Canvas Rental Mobil.

jumlah bantal leher, diskon dan member card kepada konsumen. Channels dari rental mobil adalah Kantor persewaan, website, Facebookpage, dan whatsApps. Customer Segment dari rental mobil adalah para karyawan baru, keluarga dengan pendapatan menengah kebawah, keluarga yang baru menikah, acara perniakhan dan orang yang akan melakukan mudik lebaran. Cost Structure dari rental mobil adalah pembelian mobil, perawatan mobil berkala,biaya website, biaya administrasi, dan biaya karyawan. Sedangkan pendapatan rental mobil berasal dari jasa sewa mobil.

\section{B. Menentukan Kebutuhan Rental Mobil}

Pada bari kolom bagian pertama merupakan faktor kritis dari [2] yaitu technical artefact dan services. Setelah itu terdapat 23 faktor kritis [2] yang terbagi menjadi 16 faktor kritis technical artefact dan 7 services yang disesuaikan dengan kebutuhan dari rental mobil menjadi 26 kebutuhan technical artefact dan 12 kebutuhan services.

\section{Rating Kebutuhan Rental Mobil dan T-Score}

Tahapan awal untuk mendapatkan T-score dibutuhkan total dari nilai skala setiap kebutuhan dengan menjumlah seluruh skala likert dari setiap responden untuk masing masing yang ditunjukkan pada baris Total dalam tabel 1 . Setelah itu setiap total akan di ambil rata2nya dengan menjumlahkan seluruh total dan dibagi sejumlah kebutuhan yang ada dan menghasilkan mean/ $\bar{X}$ sebesar 466.973 . Setelah diketahui nilai mean, maka dihitung standar deviasi (S) dari nilai tersebut. Standar deviasi dihitung menggunakan excel dan menghasilkan nilai 8.32. setelah didapatkan semua hitungan yang diperlukan maka T-score dapat di hitung dan hasilnya dapat dilihat di Tabel 1 .

\section{Product Service Analysis Matrix Pada Rental Mobil}

Hasil dari T-score dimasukkan kedalam sebuah tabel yang disusun sebagaimana gambar tabel 1 dimana setiap product dan service design requirement di hitung dengan menjumlahkan tingkat design requirement dan eksistensi dari hubungan antara product dan service design requirement.

Tiga dari total value yang memiliki nilai tertinggi dari product requirement design akan dijadikan sebagai desain produk yang kritis, begitu juga dengan service requirement design. Pada product requirement design yang memiliki nilai paling tinggi adalah "Fleksibilitas" dengan nilai 328,25, selanjutnya adalah "Aplikasi Pemesanan Online" dengan nilai 193,95, dan "Ketersediaan Mobil yang Diinginkan" dengan nilai 164,52. Ketiga product requirement design tersebut menjadi desain produk yang kritis.

Pada service requirement design yang memiliki nilai paling tinggi adalah "Penggunaan Smartphone Aplikasi Pemesanan Online" dengan nilai 219,36, selanjutnya adalah "Kehandalan Jasa Rental Mobil" dengan nilai 407,07 dan "Lokasi Penjemputan Mobil" dengan nilai 457,92 akan menjadi desain jasa yang kritis. Ini akan menjadi dasar desain Product Service System pada model integrasi bisnis car rental.

\section{KESIMPULAN}

\section{A. Kesimpulan}

Kebutuhan dalam rancangan model PSS bisnis rental mobil yang digunakan dalam rancangan model PSS bisnis rental mobil berjumlah 38, yang terdiri dari 26 faktor kritis technical artefact dan 12 faktor kritis services yang dapat dilihat pada tabel 1

Faktor kritis pada bisnis rental mobil berjumlah 6 dengan 3 faktor kritis dari technical artefact dan 3 faktor kritis dari service. Faktor kritis dari technical artefact adalah related product, availability, dan flexibility. Faktor kritis dari services adalah required recource, estimated result dan location of service applications.

B. Saran 
Saran untuk penelitian selanjutnya dapat meneliti model bisnis dari product and service relationship matrix dan faktor kritis yang ada [7]. Penelitian selanjutnya juga bisa meneliti model bisnis lain dengan tipe bisnis result oriented PSS [9].

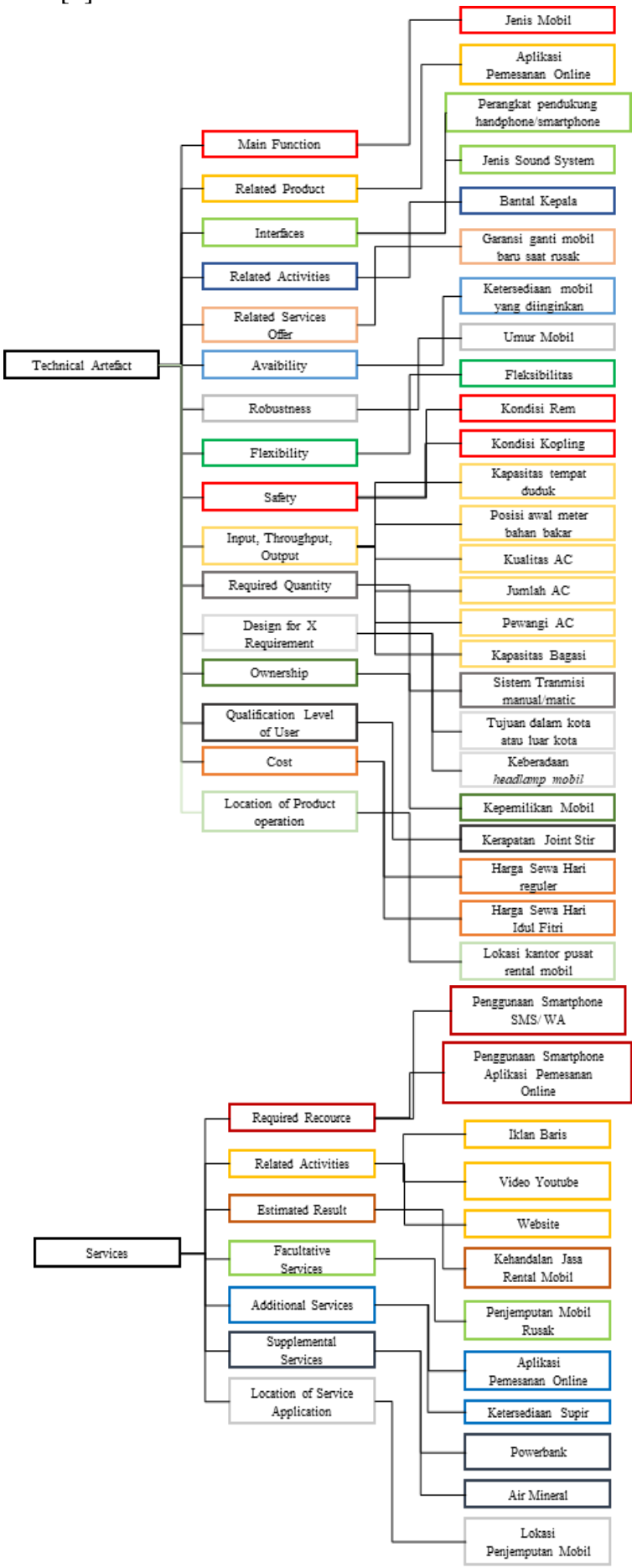

Tabel 1

Hasil Rating Kebutuhan Desain Rental Mobil dan T-Score

\begin{tabular}{|c|c|c|c|c|c|c|}
\hline No & $\begin{array}{l}\text { Kebutuhan } \\
\text { rental mobil }\end{array}$ & "untuk & Total & $\overline{\overline{\bar{X}}}$ & $\overline{\mathrm{S}}$ & $\begin{array}{c}\text { T- } \\
\text { Score }\end{array}$ \\
\hline \multicolumn{7}{|c|}{ Technical Artefact } \\
\hline $\mathrm{T} 1$ & Jenis Mobil & & 465 & & & 47,63 \\
\hline $\mathrm{T} 2$ & Aplikasi & & 479 & & & 64,65 \\
\hline & Pemesanan & online & & & & \\
\hline \multirow[t]{2}{*}{$\mathrm{T} 3 \mathrm{a}$} & $\begin{array}{l}\text { Perangkat } \\
\text { pendukung }\end{array}$ & & 479 & 466,973 & 8,32 & 64,65 \\
\hline & handphone & / & & & & \\
\hline
\end{tabular}

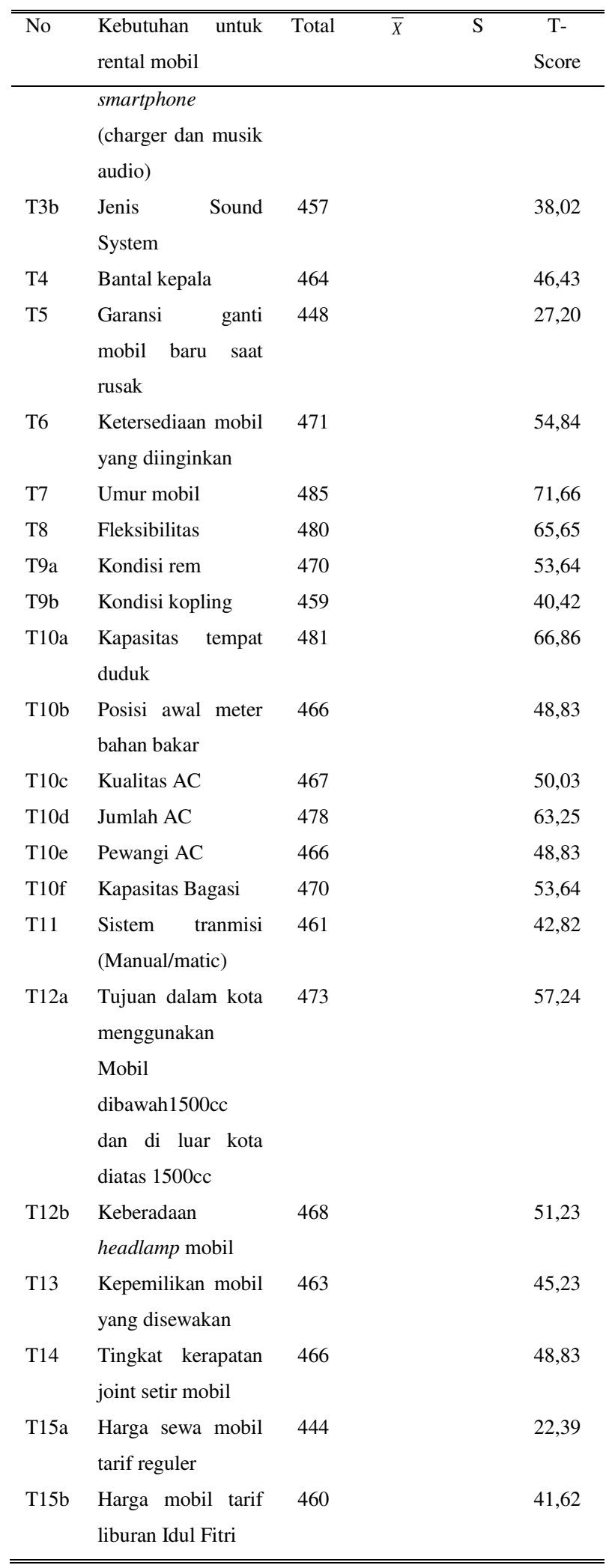

\section{DAFTAR PUSTAKA}

[1] Budi, “Mudik Lebaran 2013," Tribunnews, 2012. [Online]. Available:

http://www.tribunnews.com/regional/2013/07/23/mobil-jenismpv-paling-banyak-disewa-selama-lebaran.

[2] P. Muller, F. Schulz, and R. Stark, "Guideline to Elicit Requirement on Industrial Product Service System," 2010.

T. Prasetya, "Sukses di Bisnis Penyewaan Mobil, Atrans Rambah Bisnis Rental Via Aplikasi," tribunnews, 2017. [Online]. Available: http://www.tribunnews.com/bisnis/2017/07/20/suksesdi-bisnis-penyewaan-mobil-atrans-rambah-bisnis-rental-via- 
aplikasi

[4] Morelli, "Designing Product Service Systems: A Methodolical Exploration," Des. Issues, pp. 3-17, 2002.

[5] R. Feiberg, "Customer Service and Service Quality,” 2001.

[6] M. Goedkoop, C. van Haller, and R. P. te Riele, "Product Service Systems," 1999.

[7] S. Agus, Y. Berry, T. Benny, and A. H. Rika, "Product_service system design concept development based on product and service integration," J. Des. Res., vol. 13, 2015.

[8] P. Osterwalder and Y. Clark, T, Business Model Generation: A Handbook for Visionaries, Game Changers, and Challangers New Jersey: John Wiley \& Sons Inc, 2010.

[9] W. Reim, V. Parida, and D. Ortqvist, "Product Service System (PSS) business models and tactics- a systematic literature review," J. Clean. Prod., pp. 1-15, 2014. 